
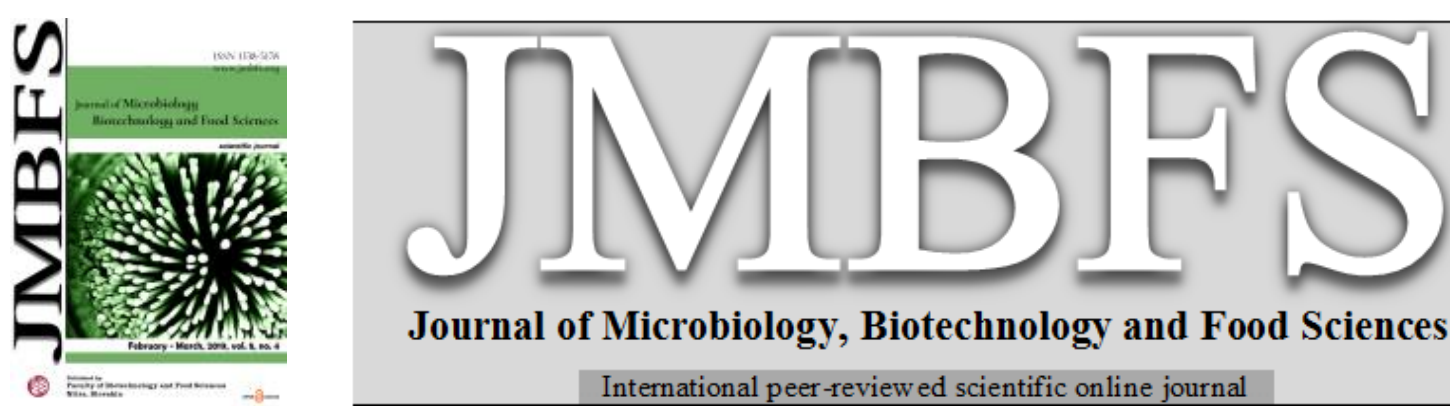

Journal of Microbiology, Biotechnology and Food Sciences

International peer-reviewed scientific online journal

\title{
ANTI QUORUM SENSING AND ANTI BIOFILM POTENTIAL OF ANOGEISSUS ACUMINATA AND MALLOTUS ROXBURGHiANUS MUELL. AgAinst PSEUDOMONAS AERUGiNOSA PAO1
}

\section{Sairengpuii Hnamte ${ }^{1}$, Pattnaik Subhaswaraj ${ }^{1}$, Sampath Kumar Ranganathan ${ }^{2}$, Dinakara Rao Ampasala ${ }^{2}$, Gangatharan Muralitharan $^{3}$, Busi Siddhardha ${ }^{*}$}

\section{$\operatorname{Address}(e s)$ :}

${ }^{1}$ Department of Microbiology, School of Life Sciences, Pondicherry University, Puducherry-605014, India.

${ }^{2}$ Centre for Bioinformatics, School of Life Sciences, Pondicherry University, Puducherry-605014, India.

${ }^{3}$ Deparment of Microbiology, School of Life Sciences, Bharathidasan University, Tiruchirappali- 620024, India.

*Corresponding author: siddhardha.busi@gmail.com

doi: 10.15414/jmbfs.2019.8.5.1135-1140

ARTICLE INFO

Received 22. 10. 2018

Revised 20. 11. 2018

Accepted 27. 11. 2018

Published 1. 4. 2019

Regular article

open 2 access

\begin{abstract}
Pseudomonas aeruginosa causes severe persistent infections in immunocompromised patients by showing tolerance conventional antibiotic therapy by virtue of specialized hierarchy of quorum sensing (QS) network. The purpose of the study was to evaluate the efficacy of two Mizoram medicinal plants i.e., Anogeissus acuminata and Mallotus roxburghianus Muell. in attenuating QS regulated P. aeruginosa virulence. The crude leaf extracts were tested for their ability to combat QS associated virulence phenotypes such as pyocyanin production, LasB elastase and Staphylolytic activity and production of biofilm determinants such as alginate and exopolysaccharide in P. aeruginosa PAO1. The gas chromatography mass spectrometry (GC-MS) analysis revealed the presence of phytocompounds, the synergistic activity of which is responsible for the anti QS activity. The in silico studies provide the binding efficacy of obtained phytochemical with QS receptor protein, LasR. The in vitro studies followed by in silico analysis demonstrated the efficacy of phytochemical of A. acuminata and M. roxburghianus Muell. in competitively inhibiting the binding of natural ligand with LasR and thereby altering production of virulence phenotypes. The efficacy in down regulating bacterial virulence shown by $A$. acuminata and $M$. roxburghianus Muell. provides promising alternatives to develop next generation anti-pathogenic agents.
\end{abstract}

Keywords: Antibiotic resistance, Biofilm, Pseudomonas aeruginosa, Quorum sensing, Virulence factors

\section{INTRODUCTION}

Microbial pathogens possess significant public health concern by showing multi drug resistance (MDR) to conventional antibiotics. In this context, the current antimicrobial approach has been shifted towards development of anti-pathogenic agents targeting quorum sensing (QS) regulated bacterial virulence rather than targeting bacterial killing (Maisuria et al., 2016). The phenomenon of QS is a cellular signaling process between bacterial cells coordinating the social behaviour through a network of discrete signaling mechanism controlling expression of different pathophysiological functions in the form of virulence factors and formation \& development of biofilm (Vasavi et al., 2016). Pseudomonas aeruginosa causes severe respiratory infections, urinary tract infections (UTIs) and other hospital acquired infections in the immunocompromised individuals under the influence of highly specialized QS regulatory network (Datta $\boldsymbol{e t}$ al., 2016). The QS system in P. aeruginosa comprises of two major LuxI/R QS machinery such as Las and Rhl system. The Las system comprises of LasR transcriptional activator which operates through a signal molecule, N-3-oxo-dodecanoyl-homoserine lactone $\left(\mathrm{C}_{12}\right.$-HSL) whereas $\mathrm{RhIR}$, as transcriptional regulator activated by a signal molecule called $\mathrm{N}$ butanoyl-homoserine lactone $\left(\mathrm{C}_{4}-\mathrm{HSL}\right)$ constitute $\mathrm{Rhl}$ system. Both Las $\mathrm{L} / \mathrm{R}$ and RhlI/R systems are intriguingly correlated with each other and coordinate the expression of virulence phenotypes such as proteases, elastases, cytotoxic pyocyanin, exopolysachharides (EPS) and rhamnolipid (Aybey and Demirkan, 2016). The ability of $P$. aeruginosa to form biofilm aids as an arsenal to the bacteria to provide tolerance against conventional antimicrobial therapy. In this context, targeting QS associated virulence could provide alternative strategies to combat QS regulated pathogenicity (Luo et al., 2016).

From last few decades, a number of synthetic, semi-synthetic and natural compounds were exploited to attenuate bacterial virulence in $P$. aeruginosa (Ouyang et al., 2016). Among the natural products, plant derived phytochemicals are exploited the most owing to their diverse chemical features, widespread bioactivities and are of potential importance in biomedical and pharmaceutical industries (Silva et al., 2016). In the present study, two medicinal plants,
Anogeissus acuminata and Mallotus roxburghianus Muell. from Mizoram, India were evaluated for their anti QS and anti-biofilm activity. A. acuminata locally known as Zairum is being actively used for stomach ache, diarrhea, as antiseptic and skin diseases like eczema, skin ulcers and dermatitis (Lalfakzuala $\boldsymbol{e t}$ al. 2007; Hemamalini et al., 2011). Meanwhile, M. roxburghianus Muell. (locally known as Zawngtenawhlung) has been used for antioxidant, anti-inflammatory and gastroprotective properties (Roy et al., 2016; Sagun et al., 2017). The aim of the present study is to evaluate the efficacy of selected medicinal plants from Mizoram, India in combating $P$. aeruginosa PAO1 pathogenicity.

\section{MATERIALS AND METHODS}

\section{Collection of Plants and Extract Preparation}

A total of twenty-five medicinal plants from different parts of Mizoram, India were collected, cleaned thoroughly, dried and grounded in the form of powder. The powdered plant materials were extracted with different solvents such as methanol, ethanol, chloroform and petroleum ether.

\section{Maintenance of culture}

The bacterial strains Chromobacterium violaceum (MTCC 2656) and $P$. aeruginosa PAO1 used for QS inhibition study were obtained from Microbial Type Culture Collection (MTCC), IMTECH, Chandigarh, India. C. violaceum was used as a biomarker strain for preliminary anti QS assay.

\section{Preliminary screening of crude plant extracts for anti-QS activity}

All the crude plant extracts were evaluated for their anti QS potential by agar well diffusion method against biomarker strain, $C$. violaceum and test organism, $P$. aeruginosa PAO1. Briefly, overnight bacterial culture was spread on top of the agar plates using sterile cotton swabs. Wells of $8 \mathrm{~mm}$ diameter were prepared and 
various concentrations of plant extracts were loaded into the wells and incubated at $37^{\circ} \mathrm{C}$ for $24 \mathrm{~h}$. DMSO was used as control (Vasavi et al., 2016).

\section{Determination of Minimal Inhibitory Concentration (MIC)}

The MIC of the selected plant extracts (A. acuminata and M. roxburghianus Muell.) against $P$. aeruginosa PAO1 was fixed as per the Clinical and Laboratory Standards Institute (CLSI) standards. All the Anti-QS assays were performed with sub-MIC dose.

\section{Anti QS activity against biomarker strain, $C$. violaceum}

\section{Violacein inhibition activity}

For violacein inhibition assay, overnight $C$. violaceum was grown on treatmen with sub-MIC of crude plant extracts at $30{ }^{\circ} \mathrm{C}$ for $24 \mathrm{~h}$. After incubation, the insoluble violacein was precipitated by centrifuging the culture at $10,000 \mathrm{rpm}$ for $10 \mathrm{~min}$. The pellet was resuspended with DMSO and vortexed for $30 \mathrm{sec}$ to solubilize the violacein. The solution was then recentrifuged $(10,000 \mathrm{rpm}, 10$ $\min$ ) and the violacein present in the supernatant were determined at $595 \mathrm{~nm}$ (D’Almeida et al., 2017).

\section{Anti QS activity of plant extracts against $P$. aeruginosa PAO1}

\section{Pyocyanin inhibition activity}

For pyocyanin inhibition assay, cell free supernatant was collected from $P$. aeruginosa PAO1 treated with sub-MIC of crude plant extracts. The supernatant was mixed with chloroform in the ratio of 3:2 and was left for phase separation. The pyocyanin from the organic phase was reextracted with $0.2 \mathrm{~N} \mathrm{HCl}$. The absorbance of the aqueous phase was measured at $520 \mathrm{~nm}$ (Luo et al., 2016).

\section{Elastolytic activity}

The effect of crude plant extracts on elastolytic activity was determined according to Luo et al. (2016). Briefly, cell free supernatant of overnight bacterial culture was mixed with Elastin Congo Red buffer ( $\mathrm{pH} \mathrm{7.5)} \mathrm{in} \mathrm{the} \mathrm{ratio}$ of $1: 9$ and incubated at $37{ }^{\circ} \mathrm{C}$ for $3 \mathrm{~h}$ with continuous shaking condition. After incubation, equal volume of sodium phosphate buffer $(0.7 \mathrm{M}, \mathrm{pH} 6.0)$ was added and placed for $30 \mathrm{~min}$ in an ice water bath followed by recentrifugation $(10,000$ $\mathrm{rpm}, 10 \mathrm{~min})$ to remove insoluble ECR. The optical density was determined at $495 \mathrm{~nm}$.

\section{Staphylolytic activity}

The ability of $P$. aeruginosa PAO1 to lyse Staphylococcus aureus cells, Staphylolytic activity was performed. S. aureus, grown overnight was boiled (10 min) followed by centrifugation at $13,000 \mathrm{rpm}, 10 \mathrm{~min}$. The obtained pellet was suspended in high salt buffer ( $\mathrm{pH} 4.5)$ and to the suspension P. aeruginosa PAO1 cell free supernatant mixed in 1:9 ratio. The absorbance of mixed suspension was determined at $495 \mathrm{~nm}$ (Alasil et al., 2015).

\section{Anti biofilm activity of plant extracts against $P$. aeruginosa PAO1}

\section{Exopolysaccharides (EPS) inhibition activity}

For EPS inhibition activity, to the cell free supernatant ethanol was added and incubated at $4{ }^{\circ} \mathrm{C}$ for $24 \mathrm{~h}$ to precipitate the EPS. After incubation, the obtained EPS was resuspended in distilled water and quantified by phenol-sulfuric acid method as described by (Rasamiravaka et al., 2015).

\section{Alginate inhibition activity}

Briefly, overnight $P$. aeruginosa PAO1 grown in presence of sub-MIC of plan extracts was mixed with $\mathrm{NaCl}(0.85 \%)$ and the mixture was centrifuged. To the supernatant, cetyl pyridinium chloride $(2 \%)$ was added and precipitated $(10,000$ $\mathrm{rpm}, 20 \mathrm{~min}$ ). The obtained pellet was dissolved in $1 \mathrm{M} \mathrm{NaCl}$, precipitated again with cold isopropanol, followed by recentrifugation. The pellet was resuspended in saline and stored at $4^{\circ} \mathrm{C}$. To the suspension, $25 \mathrm{mM}$ sodium tetraborate solution was added followed by heating $\left(100^{\circ} \mathrm{C}\right.$ for $\left.10 \mathrm{~min}\right)$, cooled at room temperature for $15 \mathrm{~min}$. To the solution, carbazole solution $(0.125 \%)$ was added and heated followed by cooling and the optical density was measured at $550 \mathrm{~nm}$ (Rasamiravaka et al., 2015).

\section{Biofilm formation activity}

Anti-biofilm activity of plant extracts was determined according to Luciardi $\boldsymbol{e}$ al. (2016). Briefly, P. aeruginosa in presence of crude plant extracts was grown for $16 \mathrm{~h}$. The planktonic cells were carefully removed and rinsed with sterile phosphate buffer saline (PBS). The biofilms attached on the surface were stained with crystal violet $(0.4 \%)$ for $10 \mathrm{~min}$. After incubation, to the crystal violet bound biofilm, absolute ethanol was added and optical density was measured at $590 \mathrm{~nm}$.

\section{Microscopic observation of biofilm by confocal laser scanning microscopy (CLSM)}

The effect of crude plant extracts on biofilm formation was analyzed by CLSM analysis as per the description given by Sethupathy et al. (2015). For CLSM analysis, $24 \mathrm{~h}$ biofilms attached to microtiter plate stained with acridine orange for $10 \mathrm{~min}$. After incubation, sterile PBS was used to remove excess stain and image of the biofilm was analyzed under microscope at $20 \mathrm{X}$ magnification.

\section{Gas Chromatography-Mass Spectrometry (GC-MS) analysis}

The phytochemical investigation of crude extract of two plants was determined using GC-MS analysis. The phytochemicals present in the spectrum was identified by NIST library database.

\section{Molecular docking studies}

The in silico analysis was carried out in Schrodinger maestro 9.2 to analyze the binding affinity of plant metabolites observed from GC-MS analysis towards LasR protein as compared to its autoinducer. The ligand binding domain of LasR protein (PDB ID: 2UV0) was obtained from Protein Data Bank. For LasR protein, grids were defined around the active aminoacid residues such as Tyr56, Trp60, Asp73, Thr75 and Ser129 where $\mathrm{C}_{12}$-HSL interacts with LasR protein (Kim et al., 2015). The ligand compounds were obtained from PubChem database and submitted for preparation in Ligprep module 2.5 in Schrodinger suite and the prepared protein and ligand were subjected for docking. The best posed ligand was selected based on hydrophobic and hydrogen bond interaction around the specified active site residues within the predefined grid box.

\section{Statistical analysis}

All the experimental data presented as mean \pm standard deviation (SD) of three independent experiments. One-way analysis of variance (ANOVA) was performed to determine the significance between both the plant extracts in combating virulence. For statistical analysis, $p<0.05$ was considered as significant.

\section{RESULTS}

\section{Screening of the plant extracts for anti-QS activity}

Among the 25 plants screened with four different solvent system, methanolic extract of A. acuminata and ethanolic extract of $M$. roxburghianus Muell. were selected for further bioassays on the basis of zone of inhibition (S1).

\section{Determination of MIC}

The MIC for A. acuminata (methanol) and $M$. roxburghianus (ethanol) was found to be $1000 \mu \mathrm{g} / \mathrm{mL}$ and $750 \mu \mathrm{g} / \mathrm{mL}$ selected as the sub-MIC. All the bioassays were performed with sub-MIC dose.

\section{Violacein inhibiton Assay}

On treatment with sub-MIC dose of $A$. acuminata and $M$. roxburghianus Muell., the relative production of violacein was significantly reduced by $70.46 \pm 3.67$ and $58.89 \pm 4.32 \%$ respectively as compared to control (Figure 1).

\section{Elastolytic activity}

On treatment with sub-MIC concentration of $A$. acuminata and $M$. roxburghianus Muell., a significant decrease in the elastolytic activity of test organism, $P$. aeruginosa PAO1 was observed with a reduction of $59.85 \pm 1.82$ and $51.65 \pm 3.88 \%$ respectively (Figure 2 ).

\section{Staphylolytic activity}

On treatment with sub-MIC dose A. acuminata and M. roxburghianus Muell. a significant reduction in Staphylolytic activity was observed with a reduction of $39.67 \pm 3.06$ and $32.39 \pm 2.23 \%$ respectively as compared to control (Figure 2).

\section{Anti-biofilm activity of plant extracts}

\section{EPS inhibition activity}

A significant decrease in EPS production in $P$. aeruginosa PAO1 was observed on treatment with sub-MIC level of $A$. acuminata and $M$. roxburghianus Muell with a reduction of $65.07 \pm 3.63$ and $52.88 \pm 3.03 \%$ respectively as compared to control (Figure 3). 


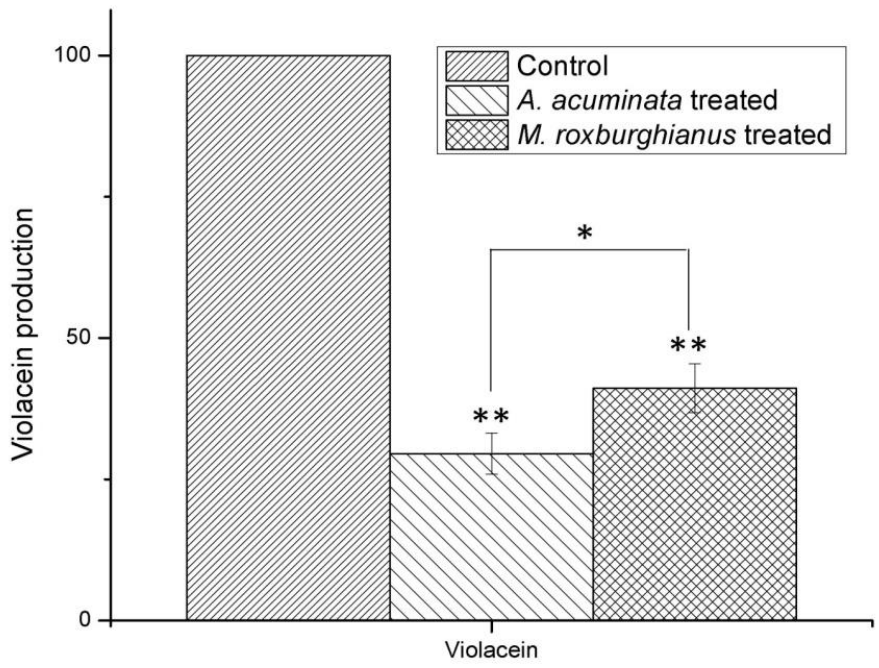

Figure 1 Effect of crude plant extract of A. acuminata and M. roxburghianus Muell. on violacein production in the biomarker strain $C$. violaceum (MTCC 2656) as compared to untreated control (normalized into $100 \%$ violacein production). Tukey's Q-test demonstrates significance between the different test groups of different sub-MIC values. *values are significantly different at $p<0.05$,

$* *$ values are significantly different at $p<0.01$, ***values are significantly different at $p<0.001,{ }^{\mathrm{NS}}$ values are not significantly different.

\section{Anti QS activity of plant extracts}

\section{Pyocyanin inhibition activity}

A. acuminata exhibited $65.24 \pm 1.72 \%$ and $M$. roxburghianus Muell. exhibited $53.97 \pm 2.15 \%$ of reduction in pyocyanin production as compared to untreated control (Figure 2).

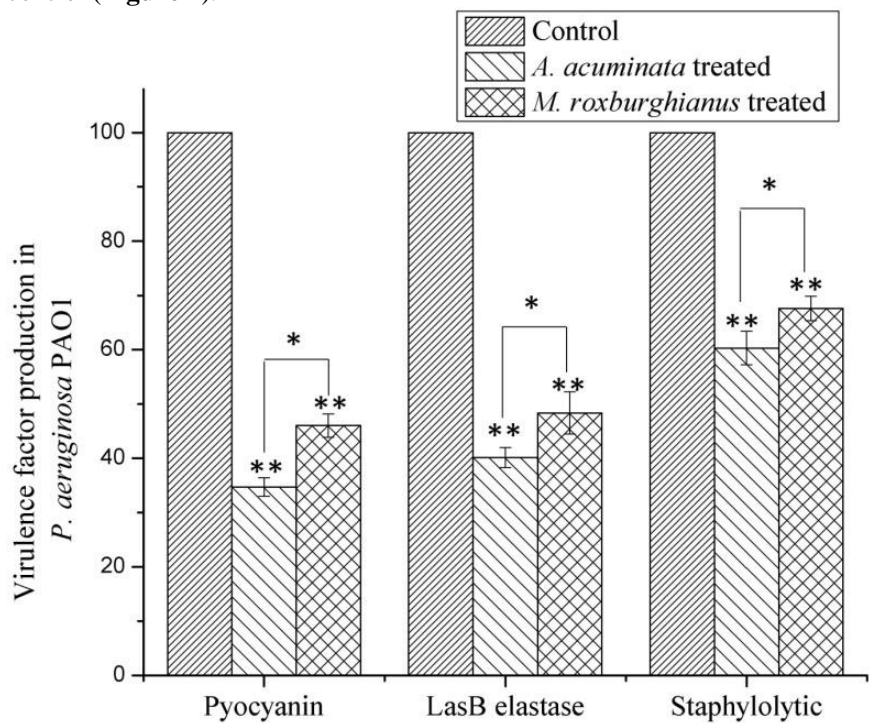

Figure 2 Effect of A. acuminata and M. roxburghianus Muell. Extract on pyocyanin production, LasB elastase and Staphylolytic activity of $P$. aeruginosa PAO1 as compared to untreated control (normalized into $100 \%$ ). *values are significantly different at $p<0.05, * *$ values are significantly different at $p<0.01$ $* * *$ values are significantly different at $p<0.001,{ }^{\mathrm{NS}}$ values are not significantly different.

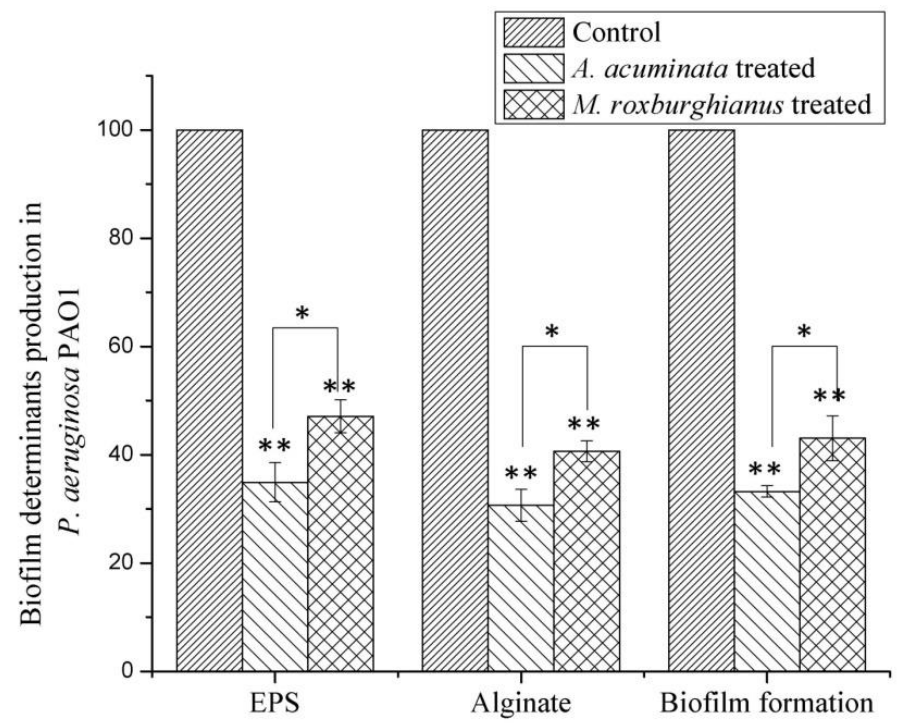

Figure 3 Effect of A. acuminata and M. roxburghianus Muell. on production of biofilm determinants (EPS and alginate) and biofilm formation in P. aeruginosa PAO1 as compared to untreated control (normalized into $100 \%$ ). *values are significantly different at $p<0.05$, **values are significantly different at $p<0.01$, $* * *$ values are significantly different at $p<0.001,{ }^{\mathrm{NS}}$ values are not significantly different.

\section{Alginate inhibition activity}

At sub-MIC of $750 \mu \mathrm{g} / \mathrm{mL}$, A. acuminata reduced the production of alginate by $69.31 \pm 2.93 \%$ as compared to $59.33 \pm 1.91 \%$ on treatment with crude extract of $M$ roxburghianus Muell. (Figure 3).

\section{Biofilm formation activity}

On treatment with sub-MIC level of A. acuminata and M. roxburghianus Muell., a significant decrease in the biofilm formation was observed with a reduction of $66.78 \pm 1.05$ and $56.96 \pm 4.15 \%$ respectively (Figure 3).

\section{CLSM analysis of biofilm}

The CLSM analysis confirmed the alteration of biofilm architecture on treatment with sub-MIC dose of $A$. acuminata and $M$. roxburghianus Muell. as compared to the control with larger aggregation of cells and thicker biofilm (Figure 4)

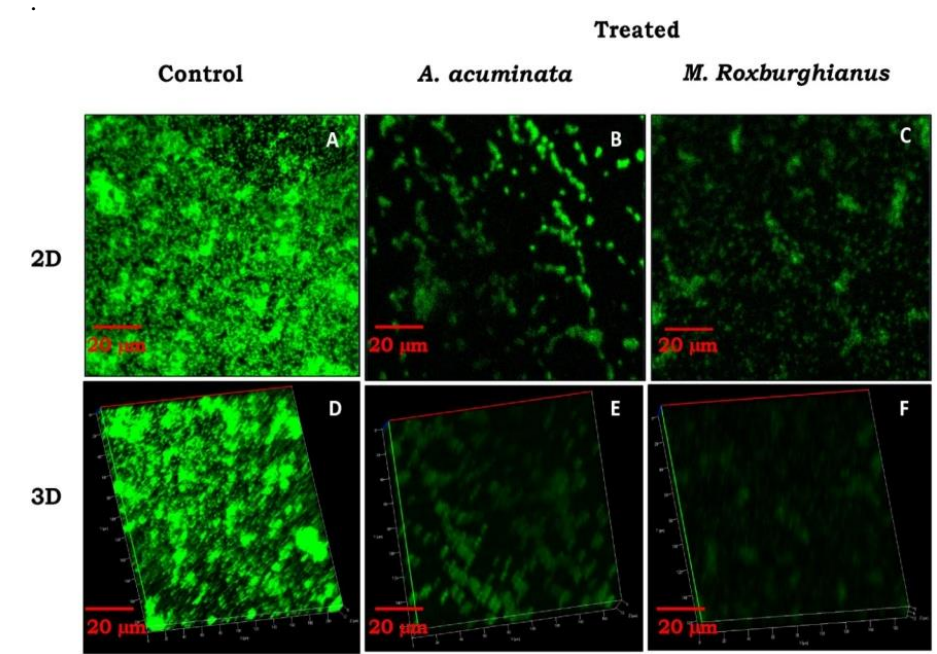

Figure 4 Effect of crude plant extract of A. acuminata and M. roxburghianus Muell. on biofilm formation as observed by CLSM analysis. A. 2D image of untreated $P$. aeruginosa PAO1 biofilm, B. 2D image of $A$. acuminata treated $P$. aeruginosa PAO1 biofilm, C. 2D image of $M$. roxburghianus Muell. treated $P$. aeruginosa PAO1 biofilm, D. 3D image of untreated $P$. aeruginosa PAO1 biofilm, E. 3D image of $A$. acuminata treated $P$. aeruginosa PAO1 biofilm, F. 3D image of $M$. roxburghianus Muell. treated $P$. aeruginosa PAO1 biofilm

\section{GC-MS analysis}

From the GC-MS analysis, A. acuminata crude extract comprised of severa phytochemicals of diverse chemical class such as phytol, $\mathrm{N}$ hexadecanoic acid, oleyl alcohol, squalene, $\alpha$ - tocopherol and betulin. Meanwhile, the presence of phytol, ethyl palmitate, squalene, $\alpha$-tocopherol, dihydrostachysterol, betulin and 
sulfurous acid and 2-propyl tridecyl ester in the ethanolic extract of $M$ roxburghianus Muell. (Table1).

Table 1 List of phytochemicals present in the crude extracts of A. acuminata and M. roxburghianus Muell. by GC-MS analysis

\begin{tabular}{|c|c|c|c|c|c|c|c|}
\hline $\begin{array}{l}\text { Sl } \\
\text { no. }\end{array}$ & $\begin{array}{c}\text { Crude plant } \\
\text { extract }\end{array}$ & Compound name & Chemical class & $\begin{array}{l}\text { Retention } \\
\text { Time }\end{array}$ & $\begin{array}{c}\text { Area } \\
\%\end{array}$ & Reported biological activity & References \\
\hline 1. & \multirow{7}{*}{$\begin{array}{c}\text { Anogeissus } \\
\text { acuminata }\end{array}$} & Phytol & Diterpene alcohol & 16.68 & 9.32 & $\begin{array}{l}\text { Anti-inflammatory, anti-QS } \\
\text { activity }\end{array}$ & (Pejin et al., 2015) \\
\hline 2. & & $\begin{array}{l}\text { N-hexadecanoic } \\
\text { acid }\end{array}$ & $\begin{array}{l}\text { Saturated fatty } \\
\text { acid }\end{array}$ & 18.30 & 18.68 & $\begin{array}{l}\text { Antioxidant and anti- } \\
\text { inflammatory activity }\end{array}$ & $\begin{array}{c}\text { (Abubakar and Majinda, } \\
\text { 2016) }\end{array}$ \\
\hline 3. & & Oleyl alcohol & $\begin{array}{l}\text { Unsaturated fatty } \\
\text { alcohol }\end{array}$ & 19.81 & 7.28 & Antibacterial activity & (Jafari et al., 2014) \\
\hline 4. & & $\begin{array}{l}\text { 1-Hexyl-1- } \\
\text { Nitrocyclohexane }\end{array}$ & Ketone & 20.015 & 13.47 & $\begin{array}{l}\text { Antimicrobial, anti- } \\
\text { inflammatory activity }\end{array}$ & $\begin{array}{c}\text { (Selvamangai and Bhaskar, } \\
\text { 2012) }\end{array}$ \\
\hline 5. & & Squalene & $\begin{array}{l}\text { Polyunsaturated } \\
\text { hydrocarbon }\end{array}$ & 24.76 & 7.14 & $\begin{array}{c}\text { Antioxidant, anticancer } \\
\text { activity }\end{array}$ & (Kim and Karadeniz, 2012) \\
\hline 6. & & $\alpha$ - tocopherol & Vitamin E & 27.11 & 20.00 & $\begin{array}{l}\text { Antioxidant, hepatoprotective } \\
\text { activity }\end{array}$ & (Palipoch et al., 2014) \\
\hline 7. & & Betulin & $\begin{array}{l}\text { Pentacyclic } \\
\text { triterpene }\end{array}$ & 29.12 & 11.19 & Immunomodulatory activity & (Pfarr et al., 2015) \\
\hline 8. & \multirow{7}{*}{$\begin{array}{l}\text { Mallotus } \\
\text { roxburghianu } \\
\text { s Muell. }\end{array}$} & Phytol & Diterpene alcohol & 16.57 & 25.4 & $\begin{array}{l}\text { Anti-inflammatory, anti-QS } \\
\text { activity }\end{array}$ & (Pejin et al., 2015) \\
\hline 9. & & Ethyl palmitate & Fatty acid esters & 18.21 & 17.59 & $\begin{array}{l}\text { Antioxidant, nematicidal } \\
\text { activity }\end{array}$ & (Kumar et al., 2010) \\
\hline 10. & & Squalene & $\begin{array}{l}\text { Polyunsaturated } \\
\text { hydrocarbon }\end{array}$ & 24.75 & 11.48 & $\begin{array}{c}\text { Antioxidant, anticancer } \\
\text { activity }\end{array}$ & (Kim and Karadeniz, 2012) \\
\hline 11. & & $\begin{array}{l}\text { Sulfurous acid, 2- } \\
\text { propyl tridecyl ester }\end{array}$ & Propyl ester & 25.32 & 1.91 & Pharmaceuticals & (Vivekraj et al., 2015) \\
\hline 12. & & $\alpha$ - tocopherol & Vitamin E & 27.11 & 14.83 & $\begin{array}{l}\text { Antioxidant, hepatoprotective } \\
\text { activity }\end{array}$ & (Palipoch et al.,2014) \\
\hline 13. & & Dihydrotachysterol & Vitamin D4 & 29.14 & 5.48 & $\begin{array}{c}\text { For treatment of } \\
\text { hypocalcemia and } \\
\text { hypothyroidism }\end{array}$ & \\
\hline 14. & & Betulin & $\begin{array}{l}\text { Pentacyclic } \\
\text { triterpene }\end{array}$ & 29.89 & 7.47 & Immunomodulatory activity & (Pfarr et al.,2015) \\
\hline
\end{tabular}

\section{Molecular docking studies}

In silico analysis of the phytochemicals present in A. acuminata and $M$ roxburghianus Muell. revealed that phytol (a common phytochemical in both crude extracts) exhibited a docking score of $-7.042 \mathrm{kcal} / \mathrm{mol}$ suggesting its affinity for LasR. In addition to phytol, sulfurous acid, 2-propyl tridecyl ester also showed promising affinity with a score of $-6.669 \mathrm{kcal} / \mathrm{mol}$ (Figure 5, Table 2).

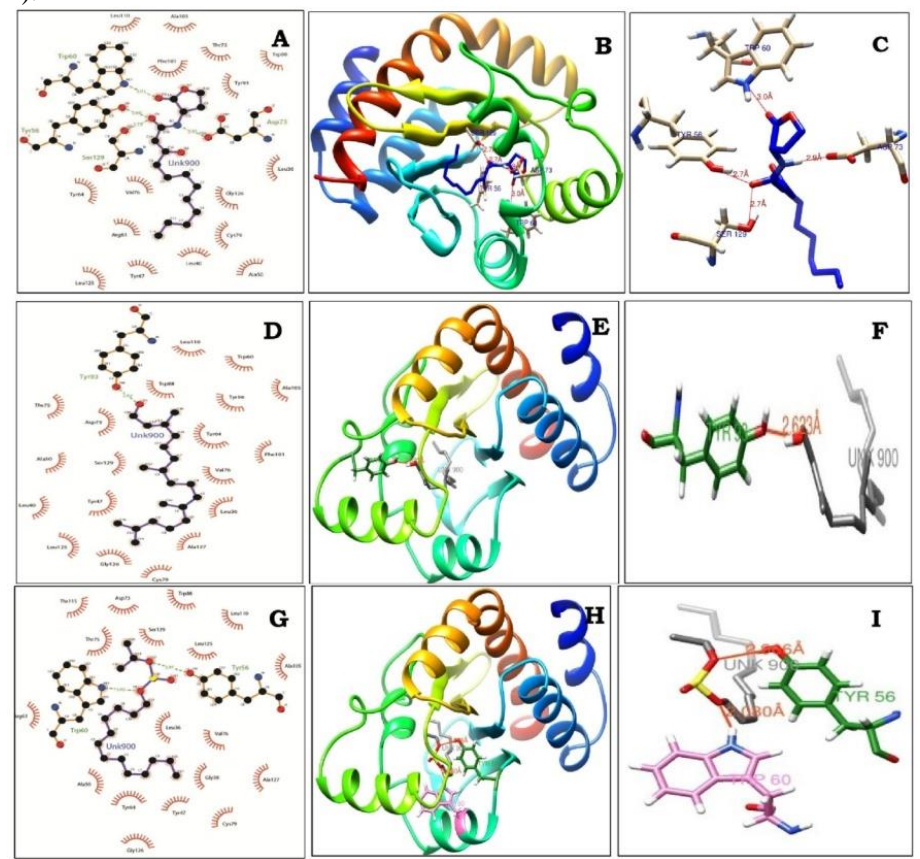

Figure 5 Docking studies: A \& B. 2D and 3D docked conformation of C12-HSL into the active site of LasR; C. 3D docked conformation of C12-HSL into the active site of LasR depicting the H-bond interaction, D\&E. 2D and 3D docked conformation of phytol into the active site of LasR, F. 3D docked conformation of phytol into the active site of LasR depicting the H-bond interaction, G\&H. 2D and 3D docked conformation of sulfurous acid, 2-propyl tridecyl ester into the active site of LasR, I. 3D docked conformation of sulfurous acid, 2 - propyl tridecyl ester into the active site of LasR. 
Table 2 Details of Docking score, hydrogen bonds and interacting residues revealed through molecular docking of selected compounds against transcriptional regulator, LasR.

\begin{tabular}{|c|c|c|c|c|c|}
\hline & Plant & Compounds & $\begin{array}{l}\text { Docking score } \\
\text { Kcal/mol }\end{array}$ & Hydrogen bond & Hydrophobic interactions \\
\hline 1. & & $\begin{array}{l}\text { 3-oxo-C12-HSL (Natural ligand } \\
\text { for LasR) }\end{array}$ & -8.489 & $\begin{array}{l}\text { Tyr56, Trp60, } \\
\text { Asp73, Ser129 }\end{array}$ & $\begin{array}{c}\text { Leu36,Try47, Tyr64, Val70, Val76, Trp88, } \\
\text { Tyr93,Ala105, Phe101,Leu110, }\end{array}$ \\
\hline 3. & & Phytol & -7.042 & Tyr 93 & Tyr 47,Ile 52,Ala 70,Leu 36 \\
\hline 4. & & N-hexadeccanoic acid & -1.979 & Tyr56 & Ala 70, Ile 52,Ala 50 \\
\hline 5. & & R-(-)-4-Methylhexanoic acid & -4.498 & $\begin{array}{l}\text { Tyr } 56, \operatorname{Thr} 75, \text { Ser } \\
129\end{array}$ & Ile 84, Ala 44, Tyr 72, Tyr 64 \\
\hline
\end{tabular}

\section{DISCUSSION}

From ancient times, medicinal plants and their phytoderivatives have been investigated for their inherent biomedical applications including QS inhibition by targeting bacterial virulence and biofilm formation. In the present study, two medicinal plants from Mizoram, India i.e. A. acuminata and M. roxburghianus Muell. were investigated for their ability to attenuate $P$. aeruginosa PAO1 virulence and biofilm formation amply supported by in silico analysis. In the present study, $C$. violaceum was used as a reporter strain to identify the efficacy of A. acuminata and M. roxburghianus Muell. in attenuating the production of violacein pigment. The methanolic extract of A. acuminata and ethanolic extract of $M$. roxburghianus Muell. significantly reduced the production of violacein as compared to control. The present results are in accordance with the earlier report suggesting the efficacy of medicinal plants in inhibiting violacein production (Tiwari et al., 2017). Pyocyanin is a class of phenazine compound produced by $P$. aeruginosa, acts as one of the major virulence determinants and is responsible for ROS generation and acute cytotoxicity. A significant decrease in the production of pyocyanin was observed on treatment with sub-MIC of $A$. acuminata and $M$. roxburghianus which was comparatively better than earlier study (Chong et al., 2011). In addition to pyocyanin production, sub-MIC dose of A. acuminata and $M$. roxburhianus Muell. also significantly modulated the elastolytic and Staphylolytic activity thereby suggesting the efficacy of test plant in modulating host immune system during host infection (Haripriyan et al.,2018).

During the biofilm formation, EPS plays crucial role in constituting the biofilm matrix and alginate, an important member of EPS family is responsible for maintaining the biofilm integrity (Powell et al., 2018). A significant reduction in EPS and alginate polysaccharides production was observed on treatment with plant extracts suggesting their role in disrupting biofilm dynamics and thereby enhancing the susceptibility of biofilm cells to the conventional antibiotics treatment (Harimawan and Ting, 2016). The biofilm disruption ability of crude plant extracts was further supported by CLSM analysis where the architecture of treated biofilm cells was significantly thinner as compared to thicker and highly compact biofilms in the untreated control.

The GC-MS analysis of the concentrated ethanol and methanol extract of the two plants resulted in the identification of an array of phytocompounds such as phytol, hexadecanoic acid, squalene, $\alpha$ - tocopherol, betulin etc. which have already been reported for a diverse range of pharmaceutical and biomedical applications. The promising anti QS and anti-biofilm activities of both the plant extracts is the result of synergistic activities of the phytochemicals present in the crude extracts thereby enhancing the activities. The presence of large quantity of phytol in both the crude extracts suggested their efficacy in attenuating $P$. aeruginosa PAO1 virulence and biofilm formation (Pejin et al., 2015). The anti QS activity of plant extracts was validated by in silico analysis, which provide an insight into the QS inhibition by certain phytochemicals present in the crude extracts by competitive binding to LasR, transcriptional regulator for production of virulence phenotypes (Kim et al., 2015).

From the preliminary anti QS and anti-biofilm activity, it was observed that both A. acuminata and M. roxburghianus Muell. extracts significantly altered the QS regulated virulence in P. aeruginosa PAO1. The presence of phytoconstituents such as phytol, squalene, betulin, hexadecanoic acid and their synergistic activities were mainly responsible for significant modulation of QS regulated virulence phenotypes and biofilm architecture. In addition, in silico molecular docking studies further corroborated the binding affinity of the phytoconstituents to LasR and thereby altering bacterial virulence in $P$. aeruginosa PAO1. The present study thus provides promising alternatives to develop anti-pathogenic agents against QS associated bacterial infections.

\section{CONCLUSION}

Our findings feature the importance of these medicinal plants as a rich source of phytocompounds for inhibiting QS. Therefore, further investigation and evaluation for these metabolites and their mechanisms are still required. This study can be regarded as an initiatory step to overcome the current problems associated with drug therapy and provide encourage research for possible use of plant metabolites as anti-QS agents.

Conflict of interest: The authors hereby declare no conflict of interest.

Acknowledgement: The authors are thankful to Bharathidasan University, Tiruchirappalli for using the Confocal Laser Scanning Microscop facility. The authors would also like to thank Sophisticated Instrumentation Facility, VIT University, VIT-SIF Lab, SAS, Chemistry Division for GC-MS Analysis.

\section{REFERENCES}

Abubakar, M.N., \& Majinda, R.R.T. (2016). GC-MS Analysis and Preliminary Antimicrobial Activity of Albizia adianthifolia (Schumach) and Pterocarpus $\begin{array}{llll}\text { angolensis } & \text { (DC). } & \text { Medicines, } & \text { 3(3), }\end{array}$ https://doi.org/10.3390/medicines3010003

Alasil, S.M., Omar, R., Ismail, S., \& Yusof, M.Y. (2015). Inhibition of quorum sensing-controlled virulence factors and biofilm formation in Pseudomonas aeruginosa by culture extract from novel bacterial species of Paenibacillus using a rat model of chronic lung infection. Int J Bacteriol, Article ID 671562. https://doi.org/ 10.1155/2015/671562

Aybey, A., \& Demirkan, E. (2016). Inhibition of quorum sensing-controlled virulence factors in Pseudomonas aeruginosa by human serum paraoxonase. $J$ Med Microbiol, 65, 105-113. https://doi.org/ 10.1099/jmm.0.000206

Chong ,Y.M., Yin, W.F., Ho, C.Y., Mustafa, M.R., Hadi, A.H.A., Awang, K., Narrima, P., Koh, C.L., Appleton, D.R., \& Chan, K.G. (2011). Malabaricone C from Myristica cinnamomea exhibits anti-quorum sensing activity. J Nat Prod, 74, 2261-2264. https://doi.org/ 10.1021/np100872k

D’Almeida, R.E., Molina, R.D.I., Viola, C.M., Luciardi, M.C., Penalver, C.N., Bardon, A., \& Arena, M.E. (2017). Comparison of seven structurally related coumarins on the inhibition of quorum sensing of Pseudomonas aeruginosa and Chromobacterium violaceum. Bioorg Chem, 73, 37-42. https://doi.org/ 10.1016/j.bioorg.2017.05.011

Datta, S., Jana, D., Maity, T.R., Samanta, A., \& Banerjee, R. (2016). Piper betle leaf extract affects the quorum sensing and hence virulence of Pseudomonas aeruginosa PAO1. 3 Biotech, 6(1), 18. https://doi.org/10.1007/s13205-015-0348- 
$\underline{8}$

Harimawan, A., \& Ting, Y.P. (2016). Investigation of extracellular polymeric substances (EPS) properties of $P$. aeruginosa and B. subtilis and their role in bacterial adhesion. Colloid Surface Biointer, 146, 459-467. https://doi.org/ 10.1016/i.colsurfb.2016.06.039

Haripriyan, J., Omanakuttan, A., Menon, N.D., Vanuopadath, M., Nair, S.S., Corriden, R., Nair, B.G., Nizet, V., \& Kumar, G.B. (2018). Clove bud oil modulates pathogenicity phenotypes of the opportunistic human pathogen Pseudomonas aeruginosa. Sci Rep, 8, 3437. https://doi.org/10.1038/s41598-01819771-7

Hemamalini, K., Ramu, A., Mallu, G., Srividya, V.V., Sravani, V., Deepak, P., \& Reddy, U.V. (2011). Evaluation of wound healing activity of different crude extracts of Anogeissus acuminata and Gymnosporia emerginata. RASAYAN J Chem, 4(2), 466-471.

Jafari, A.A., Shohrati, M., Mahmoudi, R., Hoseini, R.H., Nosratpour, S., Pajohi Alamoti, M., \& Latifi, A.M. (2014). Chemical composition and biological activities of Scrophularia striata extracts. Minerva Biotecnol, 26(3), 183-189.

Kim, H.S., Lee, S.H., Byun, Y., \& Park, H.D. (2015). 6-Gingerol reduces Pseudomonas aeruginosa biofilm formation and virulence via quorum sensing inhibition. Sci Rep, 5, 8656. https://doi.org/ 10.1038/srep08656

Kim, S.K., \& Karadeniz, F. (2012). Biological importance and applications of squalene and squalane. Adv Food Nutr Res, 65, 223-233. https://doi.org/ 10.1016/B978-0-12-416003-3.00014-7

Kumar, P.P., Kumaravel, S., \& Lalitha, C. (2010). Screening of antioxidant activity, total phenolics and GC-MS study of Vitex negundo. African J Biochem Res, 4(7), 191-195.

Lalfakzuala, R., Lalramnghinglova, H., \& Kayang, H. (2007). Ethnobotanical usages of plants in western Mizoram. Ind J Trad Knowl, 6(3), 486-493.

Luciardi, M.C., Blazquez, M.A., Cartagena, E., Bardon, A., \& Arena, M.E. (2016). Mandarin essential oils inhibit quorum sensing and virulence factors of Pseudomonas aeruginosa. LWT - Food Sci Technol, 68, 373-380. https://doi.org/10.1016/j.lwt.2015.12.056

Luo, J., Kong, J., Dong, B., Huang, H., Wang, K., Wu, L.H., Hou, C.C., Liang, Y., Li, B., \& Chen, Y.Q. (2016). Baicalein attenuates the quorum sensingcontrolled virulence factors of Pseudomonas aeruginosa and relieves the inflammatory response in $P$. aeruginosa - infected macrophages by downregulating the MAPK and NF- $\mathrm{BB}$ signal-transduction pathways. Drug Des Dev Ther, 10, 183-203. https://doi.org/ 10.2147/DDDT.S97221

Maisuria, V.B., Santos, Y.L.L., Tufenkji, N., \& Deziel, E. (2016). Cranberryderived proanthocyanidins impair virulence and inhibit quorum sensing of Pseudomonas aeruginosa. Sci Rep, 6, 30169. https://doi.org/ 10.1038/srep30169 Ouyang, J., Sun, F., Feng, W., Sun, Y., Qiu, X., Xiong, L., Liu, Y., \& Chen, Y. (2016). Quercetin is an effective inhibitor of quorum sensing, biofilm formation and virulence factors in Pseudomonas aeruginosa. J Appl Microbiol, 120(4), 966-974. https://doi.org/ 10.1111/jam.13073

Palipoch, S., Punsawad, C., Koomhin, P., \& Suwannalert, P. (2014) Hepatoprotective effect of curcumin and alpha-tocopherol against cisplatininduced oxidative stress. BMC Compl Alternative Med, 14, 111 http://doi.org/10.1186/1472-6882-14-111

Pejin, B., Ciric, A., Glamoclija, J., Nikolic, M., \& Sokovic, M. (2015). In vitro anti-quorum sensing activity of phytol. Nat Prod Res, 29(4), 374-377. https://doi.org/10.1080/14786419.2014.945088

Pfarr, K., Danciu, C., Arlt, O., Neske, C., Dehelean, C., Pfeilschifter, J.M., \& Radeke, H.H. (2015). Simultaneous and dose dependent melanoma cytotoxic and immune stimulatory activity of betulin. PLOS One, 10(3), e0118802. http://dx.doi.org/ 10.1371/journal.pone.0118802

Powell, L.C., Pritchard, M.F., Ferguson, E.L., Powell, K.A., Patel, S.U., Rye, P.D., Sakellakou, S.M., Buurma, N.J., Brilliant, C.D., Copping, J.M., Menzies, G.E., Lewis, P.D., Hill, K.E., \& Thomas, D.W. (2018). Targeted disruption of the extracellular polymeric network of Pseudomonas aeruginosa biofilms by alginate $\begin{array}{llll}\text { oligosaccharides. } \quad n p j \quad \text { Biofilm Microbiome, } & 4,\end{array}$ http://dx.doi.org/10.1038/s41522-018-0056-3

Rasamiravaka, T., Vandeputte, O.M., Pottier, L., Huet, J., Rabemanantsoa, C., Kiendrebeogo, M., Andriantsimahavandy, A., Rasamindrakotroka, A., Stevigny, C., Duez, P., \& El Jaziri, M. (2015). Pseudomonas aeruginosa biofilm formation and persistence, along with the production of quorum sensing-dependent virulence factors, are disrupted by a triterpenoid coumarate ester isolated from Dalbergia trichocarpa, a tropical legume. PLOS One, 10(7), e0132791. https://doi.org/ 10.1371/journal.pone.0132791

Roy, V.K., Chenkual, L., \& Gurusubramanian, G. (2016). Mallotus roxburghianus modulates antioxidant responses in pancreas of diabetic rats. Acta Histochem, 118(2), 152-163. https://doi.org/ 10.1016/j.acthis.2015.12.007

Sagun, K., Roy, V.K., Kumar, R.S., Ibrahim, K.S., Parimelazhagan, T., Kumar, N.S., \& Gurusubramanian, G. (2017). Antioxidant potential, anti-inflammatory activity and gastroprotective mechanisms of Mallotus roxburghianus (Muell.) against ethanol-induced gastric ulcers in Wistar albino rats. J Funct Food, 36, 448-458. https://doi.org/10.1016/j.jff.2017.07.005

Selvamangai, G., \& Bhaskar, A. (2012). GC-MS analysis of phytocomponents in the methanolic extract of Eupatorium triplinerve. Asian Pac J Trop Biomed, 2(3), S1329-S1332. https://doi.org/10.1016/S2221-1691(12)60410-9
Sethupathy, S., Nithya, C., \& Pandian, S.K. (2015). 2-Furaldehyde diethyl acetal from tender coconut water (Cocos nucifera) attenuates biofilm formation and quorum sensing-mediated virulence of Chromobacterium violaceum and Pseudomonas aeruginosa. Biofouling, 31(9-10), 721-733. https://doi.org/ 10.1080/08927014.2015.1102897

Silva, L.N., Zimmer, K.R., Macedo, A.J., \& Trentin, D.S. (2016). Plant natural products targeting bacterial virulence factors. Chem Rev, 116, 9162-9236 https://doi.org/ 10.1021/acs.chemrev.6b00184

Tiwary, B.K., Ghosh, R., Moktan, S., Ranjan, V.K., Dey, P., Choudhury, D., Dutta, S., Deb, D., Das, A.P., \& Chakraborty, R. (2017). Prospective bacterial quorum sensing inhibitors from Indian medicinal plant extracts. Lett Appl Microbiol, 65(1), 2-10. https://doi.org/10.1111/lam.12748

Vasavi, H.S., Arun, A.B., \& Rekha, P.D. (2016). Anti-quorum sensing activity of flavonoid-rich fraction from Centella asiatica L. against Pseudomonas aeruginosa PAO1. J Microbiol Immunol Infect, 49(1), 8-15. https://doi.org/ 10.1016/j.jmii.2014.03.012

Vivekraj, P., Vijayan, A., \& Anandgideon, V. (2015). Analysis of phytochemical constituents of the chloroform extracts of Abutilon hirtum (Lam.) sweet using GC-MS method. Int J Pharmacol Res, 5(8), 167-171. 